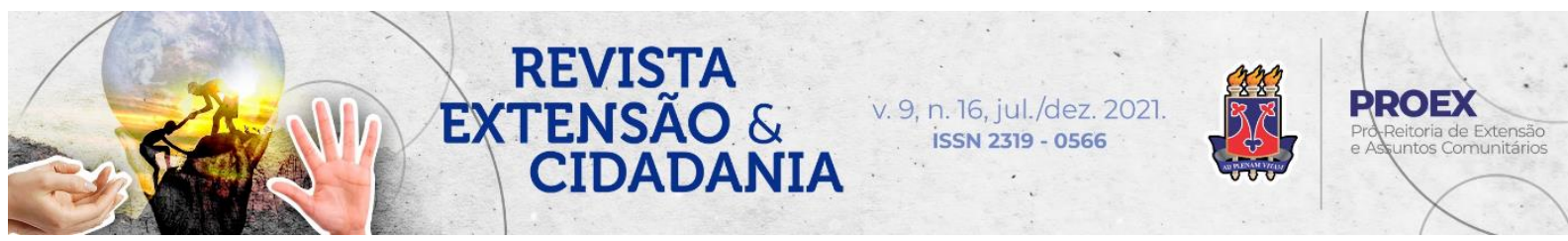

DOI: $10.22481 /$ recuesb.v9i16.9592

\title{
INICIANÇAS, CHEGANÇAS E ESPERANÇAS: EXTENSÃO, SOCIOEDUCAÇÃO E PANDEMIA
}

\section{BEGINNINGS, ARRIVALS AND HOPINGS: EXTENSION, SOCIO-EDUCATION AND PANDEMICS}

\section{PRINCIPIOS, LLEGADAS Y ESPERANZA: SOCIOEDUCACIÓN Y PANDEMIA}

\author{
Ana Nobre Pereira de Melo \\ Bruna Morais da Conceição ${ }^{2}$ \\ Larissa de Oliveira Rios Pereira Santos ${ }^{3}$ \\ Sophia Wolff Castro ${ }^{4}$
}

Resumo: O presente relato conta, a partir de quatro vozes, em diferentes momentos da formação acadêmica, o trabalho e a importância do projeto de extensão Escrevivendo a Liberdade (vinculado à Universidade do Estado do Rio de Janeiro, sob a coordenação de Vanusa Maria de Melo e Socorro Calháu), com foco na atuação durante o cenário de pandemia. Buscamos abordar não somente os percalços enfrentados pela socioeducação diante do momento sanitário vivido pelo país, como também as maneiras que o projeto encontrou para manter e fortalecer o elo entre a universidade e suas discussões e a sociedade a partir de uma perspectiva de educação não formal. Entendemos que os processos que atravessaram dentro e fora de contextos de privação de liberdade foram de intensa sobrecarga emocional que demandaram saídas e propostas de cuidado coletivo encontradas a partir da literatura. Por isso, relatamos esses contatos, leituras, trocas e inquietações trabalhadas internamente pelos integrantes do projeto em ampliação e o afeto elaborado nas nossas novas formas de interação com os adolescentes.

Palavras-chave: Extensão. Escrevivência. Socioeducação. Pandemia.

\footnotetext{
1 Graduanda de Letras, pela Universidade do Estado do Rio de Janeiro (UERJ); escrevivente no projeto Escrevivendo a liberdade. Rio de Janeiro, Brasil. Orcid: https://orcid.org/0000-0003-4192-3090. E-mail: ananobre2001@gmail.com

2 Graduanda em Direito, pela Universidade Estadual Paulista Júlio de Mesquita Filho (UNESP); bolsista PIBIC/CNPQ de Iniciação Científica; escrevivente no projeto Escrevivendo a Liberdade. Franca, São Paulo, Brasil. Orcid: https://orcid.org/0000-0002-8292-1967Ｅ-mail: brunaajm@gmail.com

${ }^{3}$ Graduada em Letras, pela Universidade Federal Fluminense (UFF), especialização em curso em Formação de Escritor na PUC-Rio; escrevivente no projeto Escrevivendo a Liberdade. Rio de Janeiro, Brasil. Orcid: https://orcid.org/0000-0002-0503-7836Ｅ-mail: lrios@id.uff.br

${ }^{4}$ Graduanda em Pedagogia na Universidade Federal do Rio de Janeiro (UFRJ); bolsista PIBIC/CNPQ de Iniciação Científica; escrevivente no projeto Escrevivendo a Liberdade. Rio de Janeiro, Brasil. Orcid: https://orcid.org/00000001-9649-6001Ｅ-mail: sophiaw.castro123@gmail.com
} 
Abstract: The present report tells, from four voices, different moments of academic formation, the work and importance of the extension project Escrevivendo a Liberdade (linked to the State University of Rio de Janeiro, under the coordination of Vanusa Maria de Melo and Socorro Calhau) focused on acting during the pandemic scenario. We seek to address not only the difficulties faced by socio-education in the face of the sanitary moment experienced by the country, but also the ways the project has found to maintain and strengthen the link between the university and its discussions and society from a perspective of non-formal education. We understand that the processes they went through inside and outside contexts of deprivation of freedom were of intense emotional overload that demanded solutions and proposals for collective care found in the literature. Therefore, we report these contacts, readings, exchanges and concerns worked internally by the members of the expanding project and the affection elaborated in our new forms of interaction with teenagers.

Keywords: Extension. Escrevivência. Socioeducation. Pandemic.

Resumen: El presente reporte relata, a cuatro voces, en diferentes momentos de la formación académica, el trabajo y la importancia del proyecto de extensión Escrevivendo a Liberdade (vinculado a la Universidad Estadual de Río de Janeiro, bajo la coordinación de Vanusa Maria de Melo y Socorro Calhau) se centró en actuar durante el escenario de la pandemia. Buscamos abordar no solo las dificultades que enfrenta la socioeducación ante el momento sanitario que vive el país, sino también las formas que ha encontrado el proyecto para mantener y fortalecer el vínculo entre la universidad y sus discusiones y la sociedad desde una perspectiva de la educación no formal. Entendemos que los procesos por los que atravesaron dentro y fuera de contextos de privación de libertad fueron de intensa sobrecarga emocional que exigieron soluciones y propuestas de cuidado colectivo que se encuentran en la literatura. Por ello, informamos de estos contactos, lecturas, intercambios e inquietudes trabajados internamente por los integrantes del proyecto en expansión y el afecto que se elabora en nuestras nuevas formas de interacción con los adolescentes.

Palabras clave: Extensión. Escrevivência. Socioeducación. Pandemia.

\section{Inicianças}

O trabalho do projeto Escrevivendo a Liberdade se iniciou em meados de março de 2019, como projeto de extensão da Faculdade de Educação, da Universidade Federal Fluminense (UFF). Entre os meses de março e julho, além de serem realizados os processos seletivos para o primeiro grupo de bolsistas, também foi desenvolvida uma formação em formato de oficina de escrita criativa, oferecida tanto para as bolsistas da época - Jéssica Montuano, Beatriz Batistela, Raissa Martins, Larissa Santos e Fabiana Pereira — quanto para a comunidade da UFF. O curso não era fechado, dessa forma, além da participação de alunos de graduação da própria universidade, contamos com a presença do público externo. A atividade era realizada uma vez por semana e se estendeu até o final do ano. Também foi

Revista Extensão \& Cidadania, v. 9, n. 16, p. 232-241, jul./dez. 2021.

ISSN 2319-0566 DOI: 10.22481/recuesb.v9i16.9592 
realizada uma oficina desse mesmo tipo com 20 servidores públicos do sistema socioeducativo. Em paralelo, também era feito um encontro semanal entre as coordenadoras do projeto Vanusa Maria de Melo e Sandra Maciel - e as bolsistas, para a discussão de textos e propostas a serem desenvolvidas no ambiente de socioeducação do estado do Rio de Janeiro.

Vale pontuar que, apesar de as coordenadoras terem atuação prévia nesses espaços, a maioria das bolsistas iriam viver esse contexto pela primeira vez, o que tornou necessário maiores estudos sobre a área, já que o tema não tem sido amplamente discutido nas ementas de licenciatura. Os principais locais de atuação são: o Departamento Geral de Ações Socioeducativas (DEGASE) - tanto a unidade masculina quanto a feminina localizados na Ilha do Governador, Rio de Janeiro - e Casa Mãe Mulher, em Belford Roxo.

Os encontros com as adolescentes na Unidade de Internação Feminina Professor Antonio Carlos Gomes da Costa (PACGC), localizada na Ilha do Governador, se iniciaram em julho, momento de férias escolares para elas, o que acabou se tornando estratégico para a viabilização de um horário na unidade feminina. A partir dessa entrada, começamos a realizar encontros semanais com as meninas, aos quais levamos livros e textos diversos de autoria majoritariamente negra, africana ou latino-americana. Dentre alguns dos autores apresentados temos: Ryane Leão, André Gabeh, Ondjaki, Marina Colassanti. Todos os encontros também impulsionavam uma produção escrita que se pautava e era incentivada pela escrevivência proposta por Conceição Evaristo, que "[...] conta as nossas histórias a partir das nossas perspectivas, é uma escrita que se dá colada à nossa vivência, seja particular ou coletiva [...]" (EVARISTO, 2017). Permanecemos com essas atividades presenciais na unidade até março de 2020, quando se iniciou a pandemia.

As atividades práticas do grupo escrevivendo passam por fundamentações teóricas relacionadas às perspectivas de educação não formal, uma vez que nossa proposta de atividade com a leitura e escrita estão desvinculadas das formas tradicionais de aprendizado. Buscamos uma educação conectada com a realidade daquelas que participam do grupo (FREIRE, 1967), capaz de escutar o que as adolescentes têm para dizer, numa troca de saberes que funciona como via de mão dupla. Dessa maneira, é possível trabalhar pela liberdade, e, coletivamente, "imaginamos esquemas para cruzar fronteiras, para transgredir. Isso é a educação como prática de liberdade" (HOOKS, 2013, p. 273). As autoras Vanusa Melo e Jéssica Mattos relatam que:

Revista Extensão \& Cidadania, v. 9, n. 16, p. 232-241, jul./dez. 2021. 
A experiência que temos vivido no projeto Escrevivendo a liberdade nos mostra que, de fato, o trabalho de formação de escritoras a partir da leitura de literatura, colabora para uma prática pedagógica em liberdade. Ao falar em liberdade, pensamos no sentido que Bell Hooks deu à transgressão, sobre ir além dos padrões impostos e das práticas escolares já conhecidas, muitas vezes não revistas e que não desejamos reproduzir também no espaço não formal de educação que estabelecemos na unidade. (MELO; MATTOS, 2020, p. 234)

Vale apontar que, em paralelo, reforçando o valor extensionista do projeto, as bolsistas e coordenadoras também escreveram três artigos em conjunto. Realizamos mais uma turma do curso de Educação em contexto de privação de liberdade, em conjunto com o Grupo de Estudos e Pesquisas em Educação Popular (GEPEP) e recebemos o prêmio Paulo Freire conferido pela Assembleia Legislativa do Estado do Rio de Janeiro (ALERJ) ${ }^{5}$.

Essas produções e a atuação realizada no período reforçam a importância de projetos de extensão como este. Em 2020, diante das surpresas e incertezas da quarentena, o Escrevivendo a Liberdade mudou de casa, seguiu sob a coordenação da professora Vanusa Maria de Melo e foi acolhido pelo projeto de extensão Do cárcere à universidade, sob coordenação da professora Socorro Calhau, passando, então, a ser vinculado à Universidade do Estado do Rio de Janeiro (UERJ).

Iniciamos 2020 com atividades regulares e uma presença constante na unidade feminina, contudo, havia as notícias de incertezas em relação ao novo coronavírus. Nesse cenário, as atividades da unidade foram suspensas e começamos nossas articulações internas para nos adaptarmos à nova realidade.

\section{Cheganças}

A pandemia da Covid-19 foi alarmada, no Brasil, no dia 13 de março de 2020, pela Organização Mundial de Saúde. Desde essa data, houve a adoção de protocolos de prevenção à pandemia, a exemplo das medidas de restrição de circulação de pessoas, a necessidade de higiene das mãos, uso de máscaras, distanciamento social e testagem de pacientes com sintomas. O primeiro semestre de 2020, então, foi tomado pelo caos, medo e incertezas, que impactaram diretamente o cotidiano da cidade. Diante das características do vírus, houve uma

\footnotetext{
${ }^{5}$ Disponível em: http://www.alerj.rj.gov.br/Visualizar/Noticia/47261. Acesso em: 28 set. 2021.
}

Revista Extensão \& Cidadania, v. 9, n. 16, p. 232-241, jul./dez. 2021. 
mobilização de alguns órgãos do Brasil para fiscalizar e colocar em prática a adoção de medidas que pudessem limitar a propagação da Covid-19 em espaços de privação de liberdade para adolescentes e jovens no país. Essas medidas foram reunidas na Recomendação n ${ }^{\circ} 62$, de 17 de março de 2020 (BRASIL, 2020), que, no seu Art.11, discorre sobre regras referentes à visitação a partir da formulação de um plano de contingência pelos gestores dos estabelecimentos.

Tendo em vista esse panorama, as atividades que aconteciam pelo Escrevivendo a Liberdade foram suspensas. O grupo, então, movimentou-se de duas formas: articulação de maneiras de manter contato com as adolescentes e foi iniciada uma dinâmica de encontros online, às sextas-feiras, com os escreviventes - são assim denominadas as pessoas que compõem o projeto Escrevivendo a Liberdade. Organizamos, então, em maio, a primeira chamada para novos integrantes, compreendendo que seria possível desenvolver um processo de formação por videoconferências.

A partir desses novos contatos, nosso grupo passou a ser composto por 18 escreviventes de formações distintas - pedagogas, professoras de português e literatura, geógrafas, historiadoras e produtora cultural. Durante esse período, estruturaram-se dentro do projeto formas de pensar atividades para os adolescentes em privação de liberdade que tentassem substituir as propostas presenciais do projeto: primeiras formas de manter contato com cartas, vídeos de contação de história, envio de livretos, kits de escrita e higiene pessoal.

Nas trocas de cartas, o principal objetivo era manter o vínculo com as adolescentes, oferecendo afeto mesmo que a distância, o conteúdo das correspondências versava sobre os sentimentos durante a pandemia, além das leituras em andamento. Já nos vídeos de contação de história, o objetivo era que as adolescentes pudessem visualizar nossas imagens e que a leitura continuasse presente, por meio da gravação dos escreviventes que se filmavam, cada um na sua residência, recitando um poema ou contando uma história curta de tema livre.

Os livretos consistiam em um compilado de textos, como cordéis e poemas, enviados para o Centro de Socioeducação Professor Antonio Carlos Gomes da Costa (Cense PACGC) e para a Casa Mãe, a seleção era feita por nós do grupo Escrevivendo, e buscamos, preferencialmente, escritores que retratam a realidade das periferias, como Sérgio Vaz, além de autoras com representatividade negra, como Maya Angelou. Os livretos eram entregues em conjunto aos kits, que incluíam itens para a escrita, como folhas, caneta, lápis entre outros, além de produtos de higiene pessoal.

Revista Extensão \& Cidadania, v. 9, n. 16, p. 232-241, jul./dez. 2021. 
Também desenvolvemos mais a nossa presença no Facebook, Instagram e Youtube com conteúdos literários voltados para as autoras e autores que são nossas referências, sempre vinculados às noções de escrevivência e da literatura como um direito humano (CÂNDIDO, 2004; CASTRILLÓN, 2011). Posteriormente, realizamos uma campanha para arrecadar fundos e ampliar a abrangência do projeto. A campanha iniciou-se em novembro de 2020 e se encerrou em janeiro de 2021, foram 14 encontros online transmitidos no Youtube, com presença de mais de 20 palestrantes, dentre eles contadores de histórias, escritores, cantores, compositores, atores, poetas, professores, todos disponíveis para conversar sobre suas vivências, literatura e liberdade.

Em paralelo a essas movimentações, não deixamos de ficar atentas às complicações que a pandemia provocou na socioeducação: até 22 de setembro de 2021 ocorreram 86 casos de adolescentes infectados pelo coronavírus no sistema socioeducativo do estado do Rio de Janeiro, o número de casos entre os servidores desse sistema era 364, chegando a 11 óbitos (BRASIL, 2021). Esses dados não são necessariamente compatíveis com a realidade, é necessário considerar os baixos índices de testagem e a falta de divulgação de informações internas.

Segundo o Mecanismo Estadual de Prevenção e Combate à tortura do Rio de Janeiro (RIO DE JANEIRO, 2020), a realidade das unidades socioeducativas durante a pandemia é marcada pela falta de políticas de isolamento, quantidade insuficiente de equipamentos de proteção individual (EPI) e condições insalubres, com escassez de produtos de higiene. Portanto, o sistema socioeducativo sofreu diversos impactos decorrentes da pandemia, além da perda de funcionários que vieram a óbito e o adoecimento daqueles que ocupam esse espaço, os adolescentes em cumprimento de medida tiveram uma série de direitos sendo violados.

Foi nesse contexto que, em outubro de 2020, entramos em uma nova e importantíssima atividade para o Escrevivendo a Liberdade: iniciamos encontros na Casa Mãe Mulher localizada em frente a uma unidade socioeducativa em Belford Roxo, na Baixada Fluminense. A iniciativa de Sandra Santos, servidora do Degase, fundadora e coordenadora da Casa Mãe Mulher, tem como objetivo o acolhimento das mães que costumam ser a pessoa da família mais presente nos dias de visitação das unidades socioeducativas.

Esse espaço, além de proporcionar um ambiente adequado para a espera dos horários disponíveis para visitação, também oferece refeições e oficinas, inclusive a nossa, dentro do projeto “Arroz, feijão e poesia". Nessa proposta, nossa atuação consiste na entrega de cestas

Revista Extensão \& Cidadania, v. 9, n. 16, p. 232-241, jul./dez. 2021. 
básicas paras as famílias que frequentam o local, além de dinâmicas relacionadas à leitura e à escrita, em um dos encontros uma das mães participantes comentou " $\mathrm{Eu}$ fui escrever com fome e não consegui, mas como é que a Carolina Maria de Jesus conseguia?” (Jussara, 10/11/2021). Essa fala traz parte da justificativa do projeto, que busca contribuir para a segurança alimentar das famílias e promover a literatura nesses espaços.

Sabemos e vemos, a cada semana em que realizamos o trabalho no espaço Casa Mãe Mulher, da realidade enfrentada pelas figuras femininas, em foco as mães, responsáveis pelo seu jovem familiar na unidade. Também se sabe da precariedade das condições externas à unidade socioeducativa, tão grande quanto interna, sem conforto às visitantes, como falta de assentos, proteção do sol e chuva, amparo. Pensando nessa cruel circunstância, a Casa Mãe Mulher marca seu espaço de diferença, desenvolvendo o papel que o Estado deveria cumprir.

\section{Esperanças}

Janeiro de 2021 se apresentou com a finalização da campanha, na qual conseguimos arrecadar quantia suficiente para viabilizar financeiramente a ampliação do projeto, possibilitando, por exemplo, a compra de livros e outros materiais. Infelizmente, a situação de saúde pública se tornava mais grave, com a oscilação e subsequente aumento de casos da Covid19. O Escrevivendo a Liberdade, assim como outras esferas da sociedade, precisou encontrar formas de se adaptar e continuar desenvolvendo o importante trabalho que fazemos. Nesse mesmo mês, além de retomar, seguindo as orientações sanitárias, as atividades na unidade feminina e em uma unidade masculina localizada no município do Rio de Janeiro.

Posteriormente, em março, uma nova entrada de escreviventes aconteceu. No contexto de pandemia, com a ampliação das ações remotas, mais pessoas de fora do Rio de Janeiro passaram a compor o projeto. $\mathrm{O}$ fato de as reuniões semanais ocorrerem de forma virtual facilita com que haja escreviventes de diferentes partes do país e até do mundo, como São Paulo, Bahia e Equador. Além disso, mesmo a distância, todos conseguem contribuir para algumas das atividades desenvolvidas pela extensão, por exemplo, auxiliando nas mídias sociais ou oferecendo oficinas nos encontros online.

Nas reuniões semanais, que acontecem remotamente, debatemos questões relacionadas à privação de liberdade a partir de sugestões de determinadas leituras, sejam elas: artigos, capítulos, teses e livros literários de poesia, contos e romance. Além disso, dentro do projeto,

Revista Extensão \& Cidadania, v. 9, n. 16, p. 232-241, jul./dez. 2021. 
existem sete núcleos: de atividades presenciais, comunicação, articulação política, contação de histórias, pesquisa, criação de material e organização de arquivos. O grupo busca o acolhimento em todas suas atividades, então, as novas escreviventes sempre tiveram suas dúvidas e anseios ouvidos num espaço aberto para partilha de sentimentos e reflexões. O fato de ser remoto traz a possibilidade de pessoas de diferentes regiões estarem nas reuniões, pensando criticamente sobre a temática, além de agregarem com sua bagagem histórica, cultural e de vida.

Nos encontros de formação dos escreviventes, lemos autoras como Silvia Castrillón e Maria Teresa Andruetto, que instigam o debate sobre a necessidade de compreender a escrita e a leitura como direitos que devem ser preservados em qualquer situação. Inclusive, evidenciamos a sua relevância no contexto de privação de liberdade. Além disso, é com a visão sobre literatura dessas autoras que compactuamos e a qual buscamos transmitir durante as oficinas com as adolescentes e com aquelas que frequentam a Casa Mãe Mulher.

Teríamos então, ao menos em nossos países, de definir a leitura e a escrita como direitos, como práticas que ajudam as pessoas a construir sua individualidade, a criar seu espaço no mundo e a estabelecer relações com os demais. Como necessidades relacionadas com a participação cidadã, e não, como estamos acostumados a vê-las como um luxo associado ao ócio e ao tempo livre ou como uma obrigação escolar. (CASTRILLÓN, 2011, p. 93-94)

Em geral, as novas integrantes possuem alguma relação com trabalhos desenvolvidos no interior de instituições privativas de liberdade. Algumas pessoas já trabalhavam ou atuaram no Degase e outros contextos similares. Nosso grupo já se aproxima a partir de uma prática que foge de um simples conteudismo e compartilha escuta para as questões que os adolescentes vivem ali dentro e fora daquele contexto, de modo a valorizar e acolher suas histórias, memórias, sonhos, angústias, visões de mundo.

A soma de experiências de novas escreviventes contribui para o desenvolvimento da extensão, que trabalha pelo diálogo entre universidade, sociedade civil e unidades socioeducativas. Entendemos que a universidade desempenha um papel relevante para a abertura desse processo de comunicação, contribuindo para ampliação do debate sobre a realidade das instituições privativas de liberdade (OLIVEIRA, 2017). Além disso, a universidade pode "protagonizar ações que promovam a redução quantitativa (menos prisões e

Revista Extensão \& Cidadania, v. 9, n. 16, p. 232-241, jul./dez. 2021. 
pessoas presas) e qualitativa (espaços menos fechados ao entorno social) do cárcere" (BRAGA, 2014, p. 369).

É pensando nisso que o Escrevivendo a Liberdade desenvolve as suas práticas extensionistas não apenas pela atuação em nossas redes virtuais e seminários, mas com a aproximação constante e os aprendizados trocados com as adolescentes presentes na socioeducação. Ademais, a leitura e a escrita configuram como uma prática de cuidado da mente diante da realidade vivenciada pelas adolescentes, possibilitando a criação de espaços para performance de liberdade dentro do confinamento (FELISBERTO, 2018). Nesse sentido, uma das adolescentes comentou "parecemos uma família, aqui, comendo coisas de ceia, conversando, lendo, nem parece cadeia” (Rosa, 21/12/2019). Além disso, as jovens poderão expressar e compreender os seus sentimentos e opiniões, em uma das leituras individuais propostas Dália (15/02/2020) disse "dá para entender eu mesma".

Diante de um contexto pandêmico tão adoecedor, o projeto se mostra importante para resgatar assuntos e práticas que nos movem como educadoras, como pessoas, como leitoras, como escritoras. As subjetividades e singularidades das pessoas que participam do grupo se encontram, se partilham, se misturam. E dentro de todas as discussões, a literatura se faz presente: ela tira do peito os sentimentos que transbordam.

\section{Referências}

BRAGA, Ana Gabriela Mendes. Universidade e prisão: inspirações teóricas e experiências referências. Revista Jurídica da Presidência, Brasília, v. 16, n. 109, p. 345-371, jun./set. 2014. Disponível em: https://revistajuridica.presidencia.gov.br/index.php/saj/article/view/15. Acesso em: 21 jun. 2021.

BRASIL. Conselho Nacional de Justiça. Boletim CNJ de monitoramento Covid-19: registro de casos e óbitos. Brasília, DF: CNJ, 2021. Disponível em: https://www.cnj.jus.br/wpcontent/uploads/2021/09/monitoramento-casos-e-obitos-covid-19-150921.pdf. Acesso em: 21 jun. 2021.

BRASIL. Conselho Nacional de Justiça. Recomendação no 62, de 17 de março de 2020. Recomenda aos Tribunais e magistrados a adoção de medidas preventivas à propagação da infecção pelo novo coronavírus - Covid-19 no âmbito dos sistemas de justiça penal e socioeducativo. Brasília, DF: CNJ, 2020. Disponível em: https://www.cnj.jus.br/wpcontent/uploads/2020/03/62-Recomenda\%C3\%A7\%C3\%A3o.pdf. Acesso em: 21 jun. 2021.

Revista Extensão \& Cidadania, v. 9, n. 16, p. 232-241, jul./dez. 2021. 
CÂNDIDO, Antônio. Vários escritos. 4. ed. reorg. pelo autor. São Paulo: Duas Cidades; Rio de Janeiro: Ouro Sobre Azul, 2004.

CASTRILlÓN, Silvia. O direito de ler e de escrever. São Paulo: Pulo do Gato, 2011.

EVARISTO, Conceição. Conceição Evaristo: 'minha escrita é contaminada pela condição de mulher negra'. Entrevistadora: Juliana Domingos de Lima. Nexo, São Paulo, 26 maio 2017.

"Em entrevista ao 'Nexo', escritora fala sobre memória, vivência, escrita e os avanços e lutas do movimento negro". Disponível em: https://www.nexojornal.com.br/entrevista/2017/05/26/ Concei\%C3\%A7\%C3\%A3o-Evaristo-\%E2\%80\%98minha-escrita-\%C3\%A9-contaminadapela-condi\%C3\%A7\%C3\%A3o-de-mulher-negra\%E2\%80\%99. Acesso em: 8 nov. 2019.

FELISBERTO, Fernanda. Palavras encarceradas: as escrevivencias em espaço prisional. In: PIRES, Thula; FREITAS, Felipe (org.). Vozes do cárcere: ecos da resistência política. Rio de Janeiro: Kitabu, 2018.

FREIRE, Paulo. Educação como prática de liberdade. Rio de Janeiro: Paz e Terra. 1967.

HOOKS, Bell. Ensinando a transgredir: a educação como prática da liberdade. São Paulo: Martins Fontes, 2013.

MELO, Vanusa Maria de; MATTOS, Jéssica Montuano Gonçalves Ramos. Experiências de autoria na socioeducação: literatura em liberdade. Fundação Universidade Federal do Tocantins. In: II JORNADA DE ESTUDOS SOBRE EDUCAÇÃO DE JOVENS E ADULTOS EM CONTEXTOS DE PRIVAÇÃO E RESTRIÇÃ̃ DE LIBERDADE, 2020, Tocantinópolis Anais [...] Tocantinópolis: UFT/PROGRAD/PROEX, 2020.

OLIVEIRA, Carolina Bessa Ferreira de. Universidade pública na prisão: desafios para além da pesquisa acadêmica. ARAC $\hat{\mathbf{E}}$ - Direitos Humanos em Revista, ano 4, n. 5, fev. 2017.

RIO DE JANEIRO (Estado). Mecanismo Estadual de Prevenção e Combate à Tortura do Rio de Janeiro. Relatório Anual 2020. Rio de Janeiro: MEPCT/RJ, 2020. Disponível em: https://drive.google.com/file/d/1_e_-WNI7cgi38wgBAjbdw0ovrDH58ZjV/view. Acesso em: 21 jun. 2021.

Recebido: 30.09.2021

Aceito: 17.11.2021

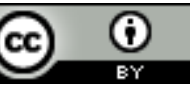

This work is licensed under a Creative Commons Attribution 4.0 International License.

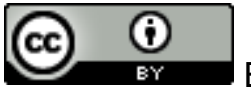

Este trabalho está licenciado com uma Licença Creative Commons - Atribuicão 4.0 Internacional.

Revista Extensão \& Cidadania, v. 9, n. 16, p. 232-241, jul./dez. 2021. 